\title{
Asymmetries in the processing of Arabic digits and number words
}

\author{
MARKUS F. DAMIAN \\ University of Bristol, Bristol, England
}

\begin{abstract}
Numbers can be represented as Arabic digits ("6") or as number words ("six"). The present study investigated potential processing differences between the two notational formats. In view of the previous finding (e.g., Potter \& Faulconer, 1975) that objects are named slower, but semantically categorized faster, than corresponding words, it was investigated whether a similar interaction between stimulus format and task could be obtained with numbers. Experiment 1 established that number words were named faster than corresponding digits, but only if the two notation formats were presented in separate experimental blocks. Experiment 2 contrasted naming with a numerical magnitude judgment task and demonstrated an interaction between notation and task, with slower naming but faster magnitude judgment latencies for digits than for number words. These findings suggest that processing of the two notation formats is asymmetric, with digits gaining rapid access to numerical magnitude representations, but slower access to lexical codes, and the reverse for number words.
\end{abstract}

Numbers are notated in one of two symbolic formats: as words (e.g., "six"), or as Arabic digits (e.g., "6"). This fact raises interesting questions about exactly how the mind represents the two notation formats. Number words are notated alphabetically, much like words in general in alphabetic writing systems such as English. Hence, the orthographic representation of a word (i.e., its letters) specifies its pronunciation, because letter symbols systematically map onto phonemes. The notation of Arabic digits, on the other hand, can be characterized as ideographic or logographic, because the visual form of a digit is only arbitrarily related to its corresponding phonological form. This raises the possibility that processing of numbers in the two notations engages fundamentally different pathways and mechanisms.

Two simple tasks that are used to compare digit and number word processing are naming aloud and numerical judgments. With number words, it is likely that the same processing routes support naming and access to conceptual knowledge that are involved in the processing of words in general. Models of visual word recognition and naming generally assume that written input can be converted to phonological codes on the basis of nonsemantic processing pathways, with some debate about whether one or more routes are required for this conversion (e.g., Coltheart, Rastle, Perry, Langdon, \& Ziegler, 2001; Plaut, McClelland, Seidenberg, \& Patterson, 1996; Seidenberg \& McClelland, 1989). Hence, if a number word (such as "six") is read out aloud, its visual input form is most likely

I thank Jeffrey Bowers, Marc Brysbaert, Yasuhiro Ito, and Joseph Tzelgov for their helpful comments and suggestions. Correspondence should be addressed to M. F. Damian, Department of Experimental Psychology, University of Bristol, 8 Woodland Road, Bristol BS8 1TN, England (e-mail: m.damian@ bristol.ac.uk). transformed into the corresponding phonological form /sıks/ without gaining access to abstract magnitude representations. ${ }^{1}$ When the task requires access to conceptual codes (such as in numerical magnitude judgments), number words, again similar to words in general, most likely gain access to semantics via an orthographic input lexicon (e.g., in Coltheart et al., 2001) or through acquired mappings from print to semantics (e.g., Plaut et al., 1996).

Arabic digits, in contrast, do not specify the phonological codes to which they correspond, and hence digits might be processed much the way objects are, rather than the way words are. Most present models of object naming (e.g., Glaser, 1992; Humphreys, Price, \& Riddoch, 1999; Theios \& Amrhein, 1989) stipulate access to semantic representations as a necessary step between visual object recognition and the access of naming codes. If the same were true for Arabic digits, then naming would also involve mandatory access to conceptual codes. Furthermore, digits would access abstract numerical codes similarly to the way objects access their meaning - that is, via a direct route from visual object recognition to conceptual representations.

Hence, if Arabic digit processing were similar to object processing in general, then digits and number words should be processed in different pathways. Number words could be assumed to gain rapid access to phonological forms, but only indirect access to meaning. In contrast, digits might gain immediate access to conceptual codes, but retrieve lexical codes only in a subsequent step. If so, number word and digit processing would be fundamentally asymmetrical. Alternatively, however, it could be that Arabic digits have processing characteristics that much resemble those of lexical items - that is, an immediate link between the visual input form and the corresponding verbal representation. This might be because single digits 
have an extremely high frequency of occurrence (e.g., Dehaene $\&$ Mehler, 1992) and because the semantic specification of numbers (i.e., numerosity) is very precise and clearly defined. In this case, digit and number word processing would be largely symmetrical: Both notation types should allow access to phonological codes without necessary semantic mediation.

Some evidence for the latter possibility comes from the neuropsychological domain. For instance, Dehaene and Cohen (1997) described a patient who performed well on digit naming but was substantially impaired when asked to decide which one of two digits was larger. Findings such as these have been taken to suggest that digits can be converted into verbal codes (and vice versa) via "asemantic transcoding routes" (e.g., Cipolotti, 1995; Deloche \& Seron, 1987), implying that digit processing is more similar to word, rather than object, processing. On the other hand, some studies investigating number processing in unimpaired populations have suggested important differences between digits and numbers. For instance, in Besner and Coltheart (1979), two Arabic digits of different physical size were presented on a computer screen, and participants judged which one was numerically larger, ignoring physical size. Nevertheless, physical magnitude influenced the speed with which the numerical size judgment was performed: Responses were faster when physical and numerical size matched than when they did not match. A different pattern was found with number words: Here, the numerical judgment was unaffected by physical size. Hence, a lexical processing mechanism appeared to be involved for number words, and an objectlike one for digits. However, subsequent studies, such as Foltz, Poltrock, and Potts (1984), have revealed significant effects even with number words (see Holender \& Peereman, 1987, for an overview) ${ }^{2}$

Fias, Reynvoet, and Brysbaert (2001) investigated whether the characteristic asymmetry found in colornaming Stroop tasks (color naming is slowed by an incongruent word, but word naming is unaffected by an incongruent color; Stroop, 1935) could be obtained with digits and number words. They showed that naming latencies of Arabic digits (e.g., "6") were substantially slowed down in the presence of an incorrect number word (e.g., "five") relative to an unrelated baseline ("xxxx"). In contrast, naming of number words was virtually unaffected by the simultaneous presence of incongruent Arabic digits. On the other hand, when the task was a parity judgment ("is the target number even or odd?"), interference was found with both notation formats. These findings suggest a fundamental difference in processing between the two notation scripts: digit, but not number word, naming is conceptually mediated, and hence an incongruent distractor interferes. Parity judgments, however, require access to conceptual information, and hence both notations are subject to interference (see Smith \& Magee, 1980, for a similar investigation into asymmetries between pictures and words). ${ }^{3} \mathrm{~A}$ similar conclusion was suggested by Fias (2001) on the basis of previous work on number processing (e.g., Dehaene, Bossini, \& Giraux,
1993) that demonstrated an association between number magnitude and response side preference: Small numbers tend to be judged faster with left-hand responses than with right-hand responses; the opposite holds for larger numbers. Fias demonstrated this effect with single-digit number words in a parity judgment task. Crucially, however, when the task was to monitor a particular phoneme in the number word, the effect vanished, suggesting that number words access semantic knowledge only when this is necessary for a particular task.

Findings such as these provide some evidence for the claim that Arabic digits and number words are processed differently. The experiments reported here contribute to this debate by focusing directly on the processing speed of digits and number words in verbal and conceptual tasks in a very simple and straightforward way. They start from one of the earliest and best documented findings in the psychology of language-namely, that it takes more time to name objects than it does to name corresponding words. This observation, first pointed out by Cattell (1885), has subsequently been replicated in more than 20 published articles (e.g., Brown, 1915; Fraisse, 1960; Glaser \& Düngelhoff, 1984; Irwin \& Lupker, 1983, to name just a few; see Ferrand, 1999, for a comprehensive listing). On the other hand, when objects or words are semantically categorized, the opposite pattern is found, with faster latencies for object than for word categorization. For instance, Potter and Faulconer(1975) demonstrated that words were named $260 \mathrm{msec}$ faster than pictures. In contrast, when participants were asked verbally to judge with a "yes" or "no" whether the picture or word was an exemplar of a category provided prior to the trial, it took $51 \mathrm{msec}$ longer to respond to words than to pictures (see also Theios \& Amrhein, 1989, for possible criticism; Seifert, 1997, for a recent replication; and Chainay \& Humphreys, 2002, for evidence that the difference in categorization speed depends to some extent on the nature of the conceptual task). This interaction between stimulus format and task is accommodated in current models of language processing by assuming that (1) words, but not objects, gain rapid access to phonological codes via one or more subsemantic routes, and (2) objects, but not words, have privileged access to conceptual codes.

A similar interaction between notation format and task could also be predicted in numerical processing if digits are processed much like objects, but number words like lexical items in general. In other words, if Arabic digits rapidly contact the conceptual system, whereas number words access semantic codes indirectly via a mental lexicon, then digits should be categorized faster than number words. Conversely, words should have an advantage over digits in naming tasks because they have rapid access to the lexicon, whereas digits have to be converted to verbal responses via the semantic system.

Experimental evidence to evaluate these predictions is scarce. Some findings suggest that tasks that require access to abstract numerical codes are performed faster on digits than on number words. For instance, Dehaene et al. (1993, Experiment 9) compared parity judgments in re- 
sponse to digits and number words ranging from 0 to 19 and found that latencies for digits were $78 \mathrm{msec}$ slower than those for words. In Dehaene et al. (1998), participants manually judged digits or number words between one and nine regarding whether they were smaller or larger than five (the crucial manipulation of presenting masked primes prior to the targets can be ignored for present purposes). Digits were categorized approximately $20 \mathrm{msec}$ faster than number words (estimated from their Figure 2; see also Naccache \& Dehaene, 2001, for similar results). Even though the effects of notation on latencies were only indirectly investigated, the results indicate an advantage of digits over number words in semantic tasks. A related finding that suggests a difference between digits and number words was reported by Ito and Hatta (2003): In their first experiment, Japanese participants were presented with two numbers of different physical size, written in Arabic, Kanji (an ideographic script), or Kana (a syllabic script), and were asked to judge manually which of the two was numerically larger. A similar congruency effect between physical and numerical size was found across the three notations. Furthermore, the fastest latencies were obtained for Arabic digits, with slower ones for Kanji, and the slowest ones for Kana. These results also suggest rapid access to numerical knowledge from digits, but slower access from other types of notation.

On the other hand, the prediction that number words are named faster than digits appears to be refuted: Ferrand (1999) asked participants in two experiments to name numbers between 0 and 19 in both notation formats. The first experiment manipulated notation format as a betweenparticipants variable and obtained a nonsignificant difference of $6.5 \mathrm{msec}$ (albeit in the predicted direction). The second experiment showed a nonsignificant difference of $6.6 \mathrm{msec}$ with notation being manipulated as a withinparticipants variable, once again in the predicted direction. These findings suggest that both notation types access corresponding phonological codes equally easily, and hence offer no support for the hypothesis that number words and digits are processed asymmetrically.

Unfortunately, these findings are somewhat ambiguous: Number naming is fast (less than $500 \mathrm{msec}$ on average), and the between-participants manipulation used in the first experiment is probably less than ideal for detecting relatively small potential differences. The second experiment—with a within-participants design-also failed to show a significant difference, which would appear to provide stronger evidence that digits and number words undergo similar processing. However, in this latter experiment the two notation formats were randomly intermixed. Recent research (e.g., Lupker, Brown, \& Colombo, 1997; Taylor \& Lupker, 2001) has revealed that latency differences between different types of stimuli are often obscured when conditions are intermixed, emerging only if stimuli are presented in "pure" blocks. Such "list composition" effects have recently been shown in other domains as well (e.g., Meyer, Roelofs, \& Levelt, 2003). A likely explanation for such effects is that when "easy" and "difficult" stimuli are blocked, speakers may adopt a differ- ential response criterion of some kind for each type, and hence differences will emerge. On the other hand, if both types are intermixed, speakers are forced to adopt an intermediate criterion that slows down fast responses and speeds up slow ones, hence obscuring the differences (see, e.g., Lupker et al., 1997; Lupker, Kinoshita, Coltheart, \& Taylor, 2003; Rastle, Kinoshita, Lupker, \& Coltheart, 2003; Taylor \& Lupker, 2001, for detailed discussions).

The important empirical observation here is that underlying processing differences between conditions sometimes emerge only if the two stimulus types are blocked. Ferrand's (1999) failure to find a significant difference between digit and number word naming should be regarded with caution-possibly, such a difference emerges only if digits and number words are presented in separate blocks. In the following experiment, the numbers one to nine were presented in one or the other notation format. Crucially, notation format was varied in experimental blocks that were either "pure" or "mixed." Only small differences were expected in the mixed condition. The crucial question was whether this difference would be accentuated in the pure condition. If so, the claim that number word and digit naming involve different processing pathways would receive some support.

\section{EXPERIMENT 1}

\section{Method}

Participants. Eight undergraduate students from the University of Bristol took part in this experiment in exchange for course credit.

Materials and Design. Stimulus notation (digits vs. number words) and mode (pure vs. mixed notation format) were manipulated as within-participants and within-items variables. The numbers zero to nine were named either as digits or as number words. They were presented in four blocks of 60 items; each stimulus was presented a total of six times per block. Mixed and pure experimental blocks alternated so that half the participants started with a mixed block and the others with a pure block; order of the pure blocks was also counterbalanced across participants. Within a block, the order of the trials was pseudorandomized so that targets were never repeated on consecutive trials.

Apparatus and Procedure. Stimuli were presented in black 18point bold Arial font on a white background in the center of a computer monitor. Number words were presented in lowercase and subtended a visual angle of between $1.9^{\circ}$ and $3.2^{\circ}$ from a viewing distance of $60 \mathrm{~cm}$. Digits subtended an angle of $0.8^{\circ}$. Responses were measured to the nearest millisecond with a voice key.

Participants were tested individually. At the beginning of the experiment, a short practice block was administered in which each target was named once in each notation in a random sequence. Then the four experimental blocks were administered. Breaks were provided between the blocks. The entire experiment consisted of 240 trials and lasted approximately $20 \mathrm{~min}$.

On each trial, a fixation cross was presented for $500 \mathrm{msec}$, followed by the target, which was shown for 1,500 msec. Latencies were measured from the onset of the target. An intertrial interval of $1,000 \mathrm{msec}$ concluded each trial. The experimenter noted down trials judged to be incorrect; latencies from these trials were later excluded.

\section{Results}

Responses on which participants had made an error $(0.3 \%)$ and response times smaller than $200 \mathrm{msec}$ or larger than $1,200 \mathrm{msec}(1.8 \%)$ were excluded from the latencies 
Table 1

Experiment 1: Response Times (RTs), Standard Deviations, and Percentage Error (PE) by Presentation Mode (Mixed vs. Pure) and Notation (Digits vs. Words)

\begin{tabular}{lrcccccc}
\hline & \multicolumn{5}{c}{ Presentation Mode } \\
\cline { 2 - 4 } \cline { 3 - 7 } Notation & RT & $S D$ & PE & & RT & $S D$ & PE \\
\hline Digits & 424 & 35 & 0.21 & & 425 & 28 & 0.42 \\
Words & 417 & 34 & 0.21 & & 402 & 30 & 0.42 \\
Difference & 7 & & 0.00 & & $23^{* *}$ & & 0.00 \\
\hline
\end{tabular}

$* * p<.01$.

analysis. Table 1 and Figure 1 show that when digits and number words were intermixed, the latency difference between them was negligible. The difference, however, was substantially larger when digits and words were presented in pure blocks.

Analyses of variance (ANOVAs) were conducted that included the factors presentation mode (mixed vs. pure) and notation (digits vs. words) as within-participants and within-items factors. No significant effect of mode was found in the analysis by participants $\left(F_{1}=0.19\right)$; however, the effect approached significance in the analysis by items $\left[F_{2}(1,9)=5.03, M S_{\mathrm{e}}=504, p=.052\right]$. The effect of stimulus notation was significant $\left[F_{1}(1,7)=14.90, M S_{\mathrm{e}}=\right.$ $\left.1,858, p=.006 ; F_{2}(1,9)=6.29, M S_{\mathrm{e}}=2,299, p=.033\right]$. Crucially, a significant interaction between mode and notation was obtained $\left[F_{1}(1,7)=6.03, M S_{\mathrm{e}}=529, p=.044\right.$; $\left.F_{2}(1,9)=6.63, M S_{\mathrm{e}}=683, p=.030\right]$, indicating that nota- tion format affected the difference in latencies between digits and number words. Simple effects on the difference between digits and number words, separately for each level of the factor presentation mode, showed no significant outcome in the mixed condition $\left[F_{1}(1,7)=2.93\right.$, $\left.M S_{\mathrm{e}}=202, p=.130 ; F_{2}(1,9)=0.74, M S_{\mathrm{e}}=238, p=.413\right]$, but a highly significant result in the pure condition $\left[F_{1}(1,7)=15.25, M S_{\mathrm{e}}=2,184, p=.006 ; F_{2}(1,9)=18.99\right.$, $\left.M S_{\mathrm{e}}=2,744, p=.002\right]$.

Error occurrences $(0.3 \%$, or 6 cases out of 1,920$)$ were considered too low to allow a meaningful analysis.

\section{Discussion}

When randomly intermixed, latency differences between digits and number words were small and not significant, hence replicating Ferrand's (1999) earlier findings. Crucially, however, when digits and number words were presented in separate experimental blocks, number words were named significantly faster than digits. These findings suggest a crucial underlying difference between the two notation types that emerges only in the pure presentation format.

We turn now to the central question of whether an interaction between notation format and task (naming vs. conceptual categorization) can be obtained. In the following experiment, the numbers one to nine were presented in one of either of the notation formats, and participants were asked to either name the stimuli or to perform a numerical magnitude judgment. An interaction between notation

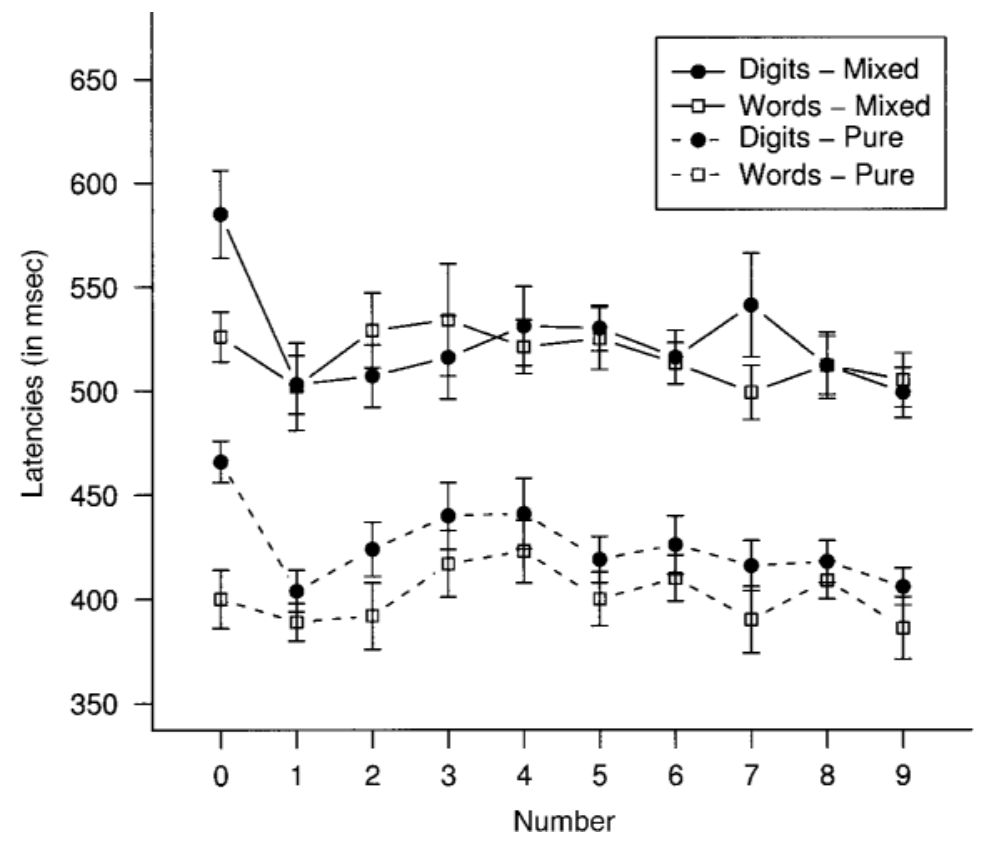

Figure 1. Response latencies for each target number, by presentation mode (mixed vs. pure) and notation (digits vs. words). Error bars indicate standard errors. To improve legibility, latencies for the mixed presentation mode have been shifted upward by 100 msec. 
and task would underscore crucial processing differences of digits and number words.

\section{EXPERIMENT 2}

\section{Method}

Participants. Eight undergraduate students from the University of Bristol, none of whom had participated in the first experiment, took part in this experiment in exchange for course credit.

Materials and Design. Task (naming vs. numerical magnitude judgment) and notation (digits vs. number words) were manipulated as within-participants and within-items variables. The numbers one to nine, with the exception of five, were presented either as digits or as number words, and were either overtly named or manually judged as to whether the target was larger or smaller than five. Half of the participants performed magnitude judgments first, and naming second, and the other half received the reverse order. Within each half, two blocks were administered, one with digits, and one with number words; the order was counterbalanced across participants. Within a block, each target was presented eight times in a random order to a total of 64 trials, with the constraint that targets were never repeated on consecutive trials. For the magnitude judgment, the mapping of small or large responses to response keys was counterbalanced across participants.

Apparatus and Procedure. These were similar to those in Experiment 1 . In the magnitude judgment task, participants pressed one of two buttons with their index fingers on a hand-held response device connected to the computer.

Participants were tested individually. At the beginning of each of the four blocks, a short practice block was administered in which each target was named in the relevant notation for the upcoming block. Breaks were provided between blocks. The entire experiment consisted of 256 trials and lasted approximately $20 \mathrm{~min}$.

The timing within each trial was the same as in the first experiment. In the naming blocks, the experimenter recorded incorrect trials.

\section{Results and Discussion}

Responses on which participants had made an error $(0.6 \%)$ and response times smaller than $250 \mathrm{msec}$ or larger than $1,200 \mathrm{msec}(0.2 \%)$ were excluded from the analysis. Table 2 and Figure 2 indicate faster latencies for number words than for digits in naming, and the opposite pattern in magnitude judgments.

ANOVAs that included the factors task (naming vs. magnitude judgment) and notation (digits vs. words) as within-participants and within-items factors indicated no significant effect of task $\left[F_{1}(1,7)=0.18, p=.068\right.$; $\left.F_{2}(1,7)=0.90, p=.374\right]$ or of notation $\left[F_{1}(1,7)=0.81, p=\right.$ $\left..400 ; F_{2}(1,7)=2.92, p=.132\right]$. Crucially, the interaction between task and notation was highly significant $\left[F_{1}(1,7)=\right.$ $31.76, M S_{\mathrm{e}}=10,357, p<.001 ; F_{2}(1,7)=60.12, M S_{\mathrm{e}}=$ $10,441, p<.001]$. Simple effects showed that in the naming task, latencies for digits were significantly slower than those for words $\left[F_{1}(1,7)=11.26, M S_{\mathrm{e}}=3,331, p=.012\right.$; $\left.F_{2}(1,7)=48.49, M S_{\mathrm{e}}=3,357, p<.001\right]$. In the magnitude judgment task, latencies for digits were significantly faster than those for words $\left[F_{1}(1,7)=13.93, M S_{\mathrm{e}}=7,432\right.$, $\left.p=.007 ; F_{2}(1,7)=30.58, M S_{\mathrm{e}}=7,495, p<.001\right]$.

Error occurrences $(0.6 \%$, or 13 cases out of 2,048$)$ were considered too low to allow a meaningful analysis.
In summary, an interaction between notation format (digits vs. number words) and task (naming vs. magnitude judgment) was obtained: Number words were named significantly faster, but conceptually categorized slower, than digits. Hence, processing of digits and number words are supported by different pathways. ${ }^{4}$

\section{GENERAL DISCUSSION}

This study investigated potential asymmetries in the way in which Arabic digits and number words access conceptual and phonological codes. The first experiment established that, when digits and number words were named in separate experimental blocks, latencies for words were significantly faster than for digits. The second experiment compared the naming of digits and number words with a manual magnitude judgment task. Digits were named slower, but categorized faster, than number words, paralleling previous findings showing that objects are semantically categorized faster, but named slower, than corresponding words (e.g., Potter \& Faulconer, 1975; Seifert, 1997). Both findings can be attributed to asymmetric processing pathways in which objects and digits gain privileged access to conceptual codes but are converted to lexical codes in a subsequent step, whereas words, including number words, gain rapid access to phonological codes but somewhat slower access to semantic knowledge. These findings are fully compatible with those recently reported by Fias et al. (2001) and described in the introduction in that they show important differences in processing between digits and number words and argue against "asemantic transcoding routes" (e.g., Cipolotti, 1995) that allow an Arabic-to-verbal conversion without the involvement of semantic codes.

The results suggest that number words, much like words in general, are read on the basis of nonsemantic processing pathways. Current models of reading (e.g., Coltheart et al., 2001) commonly assume that words with consistent spelling are predominantly read through a conversion process from graphemes to phonemes, and inconsistent ones mainly via a lexical look-up procedure. Correspondingly, number words that are spelled consistently ( six) may differ in their processing from those with inconsistent spelling (one). Figures 1 and 2 do not show such a pattern;

Table 2

Experiment 2: Response Times (RTs), Standard Deviations, and Percentage Error (PE) by Task (Naming vs. Magnitude Judgment) and Notation (Digits vs. Words)

\begin{tabular}{|c|c|c|c|c|c|c|}
\hline \multirow[b]{3}{*}{ Notation } & \multicolumn{6}{|c|}{ Task } \\
\hline & \multicolumn{3}{|c|}{ Naming } & \multicolumn{3}{|c|}{ Magnitude Judgment } \\
\hline & $\mathrm{RT}$ & $S D$ & $\mathrm{PE}$ & RT & $S D$ & $\mathrm{PE}$ \\
\hline Digits & 486 & 41 & 0.39 & 443 & 54 & 0.39 \\
\hline Words & 457 & 32 & 0.39 & 486 & 63 & 0.98 \\
\hline Difference & $29 *$ & & 0.00 & $-43 * *$ & & -0.59 \\
\hline
\end{tabular}

$* p<.05 . \quad * * p<.01$. 


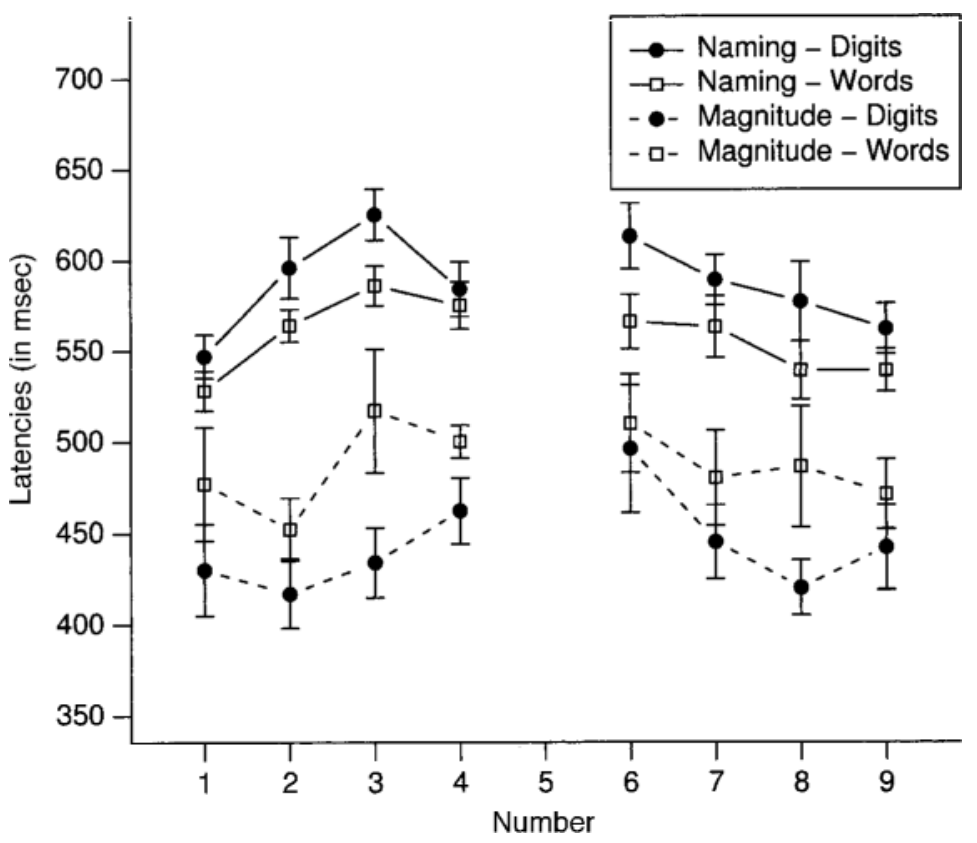

Figure 2. Response latencies for each target number, by task (naming vs. magnitude judgment) and notation (digits vs. words). Error bars indicate standard errors. To improve legibility, latencies for the naming task have been shifted upward by $100 \mathrm{msec}$.

however, single-digit number words are most likely too frequent in occurrence to reveal such differences.

How do the central findings relate to current models of number processing? Most models agree that Arabic digits and number words are processed in separate input modules. For instance, the framework proposed by McCloskey (1992) assumes that two different input systems map onto a common abstract magnitude representation, and onto phonologicalword forms in a subsequent step. Processing of number words and digits is largely symmetrical: In tasks that require access to conceptual codes, both formats access abstract magnitude representations in a parallel fashion. In tasks that require access to phonological codes, both formats access these codes via semantic representations. This model could not easily accommodate the present results. To account for the finding that number words are named faster than digits, one could assume that the route between the digit processing module and the semantic system is slower than the corresponding link between number word processing and semantics. However, this would entail slower numerical judgments for digits than for number words, which is the opposite of what was found. ${ }^{5}$

An alternative framework, the "triple-code" model developed by Dehaene (1992; see also Dehaene \& Cohen, 1995), specifies three different modules: a "visual Arabic" system, which mediates Arabic numeral input and output and multidigit calculations; an "auditory-verbal" system, which mediates verbal-written and spokeninput and output, as well as simple addition and multipli- cation tables; and an "analogue magnitude" system, which supports subitizing, estimation, and approximate calculation. All three subsystems map directly onto each other. Specifically, Arabic codes can be transformed, via an "asemantic transcoding route," into verbal codes (and vice versa) without intervening access to abstract magnitude codes. This framework assumes that number words directly access the auditory-verbal modules, which support naming. In contrast, digits access the visual Arabic system and have to be converted to the auditory-verbal system via the asemantic route. Assuming that the conversion process takes some time, the model does predict that number words are named faster than digits. On the other hand, both notation types access the analogue magnitude module in a parallel fashion. To account for the finding that digits are numerically categorized faster than number words, additional assumptions are required - for example, that the link between digit processing and the conceptual system is stronger than the corresponding link for number words. This possibility is difficult to rule out at present; however, the results reported here highlight the need to be explicit about such assumptions.

Yet another framework, the "preferred entry code" hypothesis of Noel and Seron (1993), assumes that each individual has a preferred concrete entry code to which numbers are initially converted. Some individuals may convert all input forms, including Arabic digits, to a verbal format before accessing abstract numerical codes; others may use Arabic digits as the preferred entry code to conceptual knowledge. The present findings do not pro- 
vide evidence for this claim. On the contrary, the obtained interaction between notation format and task was highly consistent: 8 out of 8 participants showed faster average latencies for naming number words than for digits, and 7 out of 8 showed slower latencies in size judgments on number words than on digits.

The results are clearly most compatible with the account introduced by Fias (2001), in which digits are processed along a central semantic route whereas written number words can access either semantics or their phonological codes directly. Prima facie, the interaction between notation format and task rules out the possibility that digits, much like words, could be converted to phonological codes via asemantic transcoding routes. However, it is possible that asemantic routes between digits and corresponding phonological codes exist, but act too slowly to contribute to the naming latencies of digits (see Fias, 2001, and Fias et al., 2001, for a discussion). This possibility, although difficult to refute experimentally, would have the benefit of accounting for certain neuropsychologicalfindings (such as Cipolotti, 1995; Dehaene \& Cohen, 1997) that are difficult to explain otherwise. However, it appears that such asemantic pathways do not contribute much to normal number processing.

The proposed similarity between digits and pictorial stimuli probably breaks down outside the realm of singledigit numbers. The encoding and decoding of multidigit numbers is combinatorial in nature and hence implements a rigid syntactic structure. For instance, the stimulus " 24 " will be pronounced "twenty-four" in English, but "fourand-twenty" in German and Dutch. Furthermore, single digits have different meanings depending on their position in a digit string (e.g., "2" means "two" in 32, "twenty" in 24 , and "twelve" in 12; Deloche \& Seron, 1987). Hence, the decoding of multidigit numbers (both in Arabic and verbal format) into meaning involves lexical and syntactic processes before abstract numerical codes can be accessed, and the same probably holds for the naming of complex numbers. It is thus unlikely that the proposed properties of single digits and corresponding number words also hold for more complex numbers. Instead, models such as McCloskey's (1992), which propose lexical and syntactic codes in the processing modules for Arabic digits as well as for number words (and hence an entirely symmetrical structure for digits and number words), are probably more adequate. For single-digit numbers, however, the present findings suggest privileged access of digits to conceptual codes, but slower access to lexical representations, and the reverse pattern for number words.

\section{REFERENCES}

Besner, D., \& ColtheArT, M. (1979). Ideographic and alphabetic processing in skilled reading of English. Neuropsychologica, 17, $467-$ 472 .

Brown, W. (1915). Practice in associating color-names with colors. Psychological Review, 22, 45-55.

Cattell, J. M. (1885). Uber die Zeit der Erkennung und Benennung von Schriftzeichen, Bildern und Farben [The time it takes to recognize and name letters, pictures, and colors]. Philosophische Studien, 2, 635-650.
Chainay, H., \& Humphreys, G. W. (2002). Privileged access to action for objects relative to words. Psychonomic Bulletin \& Review, 9, 348355 .

Cipolotti, L. (1995). Multiple routes for reading words, why not numbers? Evidence from a case of Arabic numeral dyslexia. Cognitive Neuropsychology, 12, 313-342.

Coltheart, M., Rastle, K., Perry, C., Langdon, R., \& Ziegler, J. (2001). DRC: A dual route cascaded model of visual word recognition and reading aloud. Psychological Review, 108, 204-256.

Dehaene, S. (1992). Varieties of numerical abilities. Cognition, 44, 1-42. Dehaene, S., Bossini, S., \& Giraux, P. (1993). The mental representation of parity and number magnitude. Journal of Experimental Psychology: General, 122, 371-396.

Dehaene, S., \& Cohen, L. (1995). Towards an anatomical and functional model of number processing. Mathematical Cognition, 1, 83-120.

Dehaene, S., \& Cohen, L. (1997). Cerebral pathways for calculation: Double dissociation between rote verbal and quantitative knowledge of arithmetic. Cortex, 33, 219-250.

Dehaene, S., \& Mehler, J. (1992). Cross-linguistic regularities in the frequency of number words. Cognition, 43, 1-29.

Dehaene, S., Naccache, L., Le Clec'H, G., Koechlin, E., Mueller, M., Dehaene-Lambertz, G., van de Moortele, P.-F., \& Le Bihan, D. (1998). Imaging unconscious semantic priming. Nature, 395, 597 600.

Deloche, G., \& Seron, X. (1987). Numerical transcoding: A general production model. In G. Deloche \& X. Seron (Eds.), Mathematical disabilities: A cognitive neuropsychological perspective (pp. 137170). Hillsdale, NJ: Erlbaum.

Ferrand, L. (1999). Why naming takes longer than reading? The special case of Arabic numbers. Acta Psychologica, 100, 253-266.

FIAS, W. (2001). Two routes for the processing of verbal numbers: Evidence from the SNARC effect. Psychological Research, 65, 250-259.

Fias, W., Reynvoet, B., \& Brysbaert, M. (2001). Are Arabic numerals processed as pictures in a Stroop interference task? Psychological Research, 65, 242-249.

Foltz, G. S., Poltrock, S. E., \& PotTs, G. R. (1984). Mental comparison of size and magnitude: Size congruity effects. Journal of Experimental Psychology: Learning, Memory, \& Cognition, 10, 442-453.

FRAISSE, P. (1960). Recognition time measured by verbal reaction to figures and words. Perceptual \& Motor Skills, 11, 204-211.

Glase R, W. R. (1992). Picture naming. Cognition, 42, 61-105.

Glaser, W. R., \& DÜNGELhOFF, F.-J. (1984). The time course of picture-word interference. Journal of Experimental Psychology: Human-Perception \& Performance, 10, 640-654.

HeniK, A., \& TZELgov, J. (1982). Is three greater than five? The relation between physical and semantic size in comparison tasks. Memory \& Cognition, 10, 389-395.

HinO, Y., \& LUPKER, S. J. (1996). The effects of polysemy in lexical decision and naming. Journal of Experimental Psychology: Learning, Memory, \& Cognition, 22, 1331-1356.

Hino, Y., Pexman, P. M., \& LuPKer, S. J. (2002). Ambiguity and synonymy effects in lexical decision, naming, and semantic categorization tasks: Interactions between orthography, phonology, and semantics. Journal of Experimental Psychology: Learning, Memory, \& Cognition, 28, 686-713.

Holender, D., \& PeEreman, R. (1987). Differential processing of phonographic and logographic single-digit numbers by the two hemispheres. In G. Deloche \& X. Seron (Eds.), Mathematical disabilities: A cognitive neuropsychological perspective (pp. 43-85). Hillsdale, NJ: Erlbaum.

Humphreys, G. W., Price, C. J., \& Riddoch, M. J. (1999). From objects to names: A cognitive neuroscience approach. Psychological Research, 62, 118-130.

IRWIN, D. I., \& LUPKER, S. J. (1983). Semantic priming of pictures and words: A levels of processing approach. Journal of Verbal Learning \& Verbal Behavior, 22, 45-60.

Iто, Y., \& HAтTA, T. (2003). Semantic processing of Arabic, Kanji, and Kana numbers: Evidence from interference in physical and numerical size judgments. Memory \& Cognition, 31, 360-368.

LuPKER, S. J., BROWN, P., \& COLOMBO, L. (1997). Strategic control in a naming task: Changing routes or changing deadlines? Journal of Ex- 
perimental Psychology: Learning, Memory, \& Cognition, 23, 570590.

Lupker, S. J., Kinoshita, S., ColtheArt, M., \& TAYlor, T. E. (2003). Mixing costs and mixing benefits in naming words, pictures, and sums. Journal of Memory \& Language, 49, 556-575.

MCCloskey, M. (1992). Cognitive mechanisms in numerical processing: Evidence from acquired dyscalculia. Cognition, 44, 107-157.

Meyer, A. S., Roelofs, A., \& Levelt, W. J. M. (2003). Word length effects in object naming: The role of a response criterion. Journal of Memory \& Language, 48, 131-147.

NACCACHe, L., \& Dehaene, S. (2001). Unconscious semantic priming extends to novel unseen stimuli. Cognition, 80, 223-237.

Noel, M. P., \& Seron, X. (1993). Arabic number reading deficit: A single case study. Cognitive Neuropsychology, 10, 317-339.

PeCHER, D. (2001). Perception is a two-way junction: Feedback semantics in word recognition. Psychonomic Bulletin \& Review, 8, 545-551.

Plaut, D. C., McClelland, J. L., Seidenberg, M., \& Patterson, K. (1996). Understanding normal and impaired word reading: Computational principles in quasi-regular domains. Psychological Review, 103, 56-115.

Potter, M. C., \& Faulconer, B. A. (1975). Time to understand pictures and words. Nature, 253, 437-438.

Rastle, K., Kinoshita, S., Lupker, S. J., \& Coltheart, M. (2003). Cross-task strategic effects. Memory \& Cognition, 31, 867-876.

SeidenberG, M. S., \& MCClelland, J. L. (1989). A distributed developmental model of word recognition. Psychological Review, 96, 523 568.

SEIFERT, L. S. (1997). Activating representations in permanent memory: Different benefits for pictures and words. Journal of Experimental Psychology: Learning, Memory, \& Cognition, 23, 1106-1121.

Smith, M. C., \& MageE, L. E. (1980). Tracing the time course of picture-word processing. Journal of Experimental Psychology: General, 109, 373-392.

Strain, E., Patterson, K., \& Seidenberg, M. S. (1995). Semantic effects in single-word naming. Journal of Experimental Psychology: Learning, Memory, \& Cognition, 21, 1140-1154.

STROOP, J. R. (1935). Studies of interference in serial verbal reactions. Journal of Experimental Psychology, 18, 643-662.

TAYLOR, T. E., \& LUPKER, S. J. (2001). Sequential effects in naming: A time-criterion account. Journal of Experimental Psychology: Learning, Memory, \& Cognition, 27, 117-138.

THEIOS, J., \& AMRHEIN, P. C. (1989). Theoretical analysis of the cognitive processing of lexical and pictorial stimuli: Reading, naming, and visual and conceptual comparisons. Psychological Review, 96, 5-24.

\section{NOTES}

1. Some evidence suggests that semantic variables influence naming latencies of words (e.g., Hino \& Lupker, 1996; Hino, Pexman, \& Lupker, 2002; Pecher, 2001; Strain, Patterson, \& Seidenberg, 1995). However, these findings do not contradict the assumption that in word naming, access to conceptual codes does not constitute a necessary step in the retrieval of naming codes.

2. Interestingly, interference is also found when the physical size of pairs of digits has to be judged while the numerical magnitude has to be ignored (Henik \& Tzelgov, 1982); however, I am not aware of a comparison between digits and number words on this version of the task.

3. Fias et al. (2001) discussed the possibility that digits can in principle be named via a subsemantic digit-to-sound pathway, but that this route is too slow to contribute to response times. This possibility will be taken up again in the General Discussion with regard to the findings from the present study.

4. An alternative task that could be used to assess the speed of access to conceptual number codes is to ask participants to categorize numbers into odd or even (parity judgment). Like the numerical magnitude task, parity judgments require access to abstract numerical codes. However, because of previous claims (e.g., Dehaene et al., 1993) that parity information might be stored in a format that is specific to the Arabic notation, the interpretation of the findings is perhaps more difficult than that with the numerical magnitude judgment task. I did, however, perform an additional experiment that compared naming with parity judgment on digits and number words, and obtained the same interaction between task and notation as that shown in Experiment $2\left[F_{1}(1,7)=27.33, p=.001\right.$; $\left.F_{2}(1,9)=57.03, p<.001\right]$.

5. In fairness to McCloskey (1992), however, one should note that this framework emphasizes complex number processing tasks such as multidigit processing and arithmetic. Indeed, McCloskey discussed potential subsemantic conversion routes between single-digit number words and corresponding phonological codes. However, the relative importance of such routes was somewhat downplayed because they clearly do not have much of a functional role in complex numerical tasks. If the existence of such routes were granted at least for single-digit number words, then the model could relatively easily accommodate the present findings.

(Manuscript received April 3, 2003; revision accepted for publication August 30, 2003.) 